\title{
ОСОБЕННОСТИ ВНЕСУДЕБНОГО ПОРЯДКА РАЗРЕШЕНИЯ АДМИНИСТРАТИВНО-ПРАВОВОГО СПОРА
}

\section{FEATURES OF THE OUT-OF-COURT PROCEDURE FOR RESOLVING AN ADMINISTRATIVE-LEGAL DISPUTE}

V. Ternovskiy

Summary. This article analyzes the out-of-court procedure for resolving an administrative-legal dispute both from the point of view of theoretical and practical application. The issues of alternative resolution of a public dispute on the example of foreign countries are touched upon. The practical implementation and application of various methods of administrative conflict resolution within the framework of the administrative justice of Russia is justified. The theoretical necessity of changing the approach to public administration of executive authorities is substantiated. Definition of concepts and methods of administrative protection of subjects of administrative and legal disputes, their legal significance and legal consolidation in science and law enforcement activities.

Keywords: administrative law, public administration, executive authorities, administrative and legal dispute, legal entities, alternative methods of dispute resolution, administrative justice.

\author{
Терновский Виталий Анатольевич \\ Аспирант, Московский финансово-юридический \\ университет \\ vat13list@mail.ru
}

Аннотация. В данной статье проводится анализ внесудебного порядка разрешения административно-правового спора как с точки зрения теоретического, так и практического применения. Затрагиваются вопросы альтернативного разрешения публичного спора на примере зарубежных стран. 0босновывается практическое внедрение и применение различных способов административного разрешения конфликта в рамках административной юстиции России. Обосновывается теоретическая необходимость изменения подхода к публичному администрированию органов исполнительной власти. Определение понятий и способов административной защиты субъектов административно-правовых споров их юридическое значение и правовое закрепление в науке и правоприменительной деятельности.

Ключевые слова: административное право, публичное администрирование, органы исполнительной власти, административно-правовой спор, субъекты права, альтернативные способы разрешения спора, административная юстиция.
B настоящей главе автор проводит исследование внесудебного (административного) порядка разрешения публичных споров возникающих между субъектами правоотношений, а также альтернативные способы разрешения возникших противоречий.

На сегодняшний день приоритет рассмотрения публично-правовых споров отдается судебному процессу, посредством подачи административного иска в суд, однако актуальными и все более обоснованными становятся альтернативные внесудебные способы разрешения административных споров, что требует осмысления не только в научном, но и на законодательном уровне. Именно об этом говорится в Рекомендациях Комитета министров Совета Европы REC (2001) 9 государствам-членам «Об альтернативах судебному разбирательству споров между органами исполнительной власти и частными лицами» [4, с. 111-124].

Рассматривая внесудебный порядок разрешения споров, мы видим, что такой порядок предусматривает закрепление полномочий или пра́ва (например, применительно к третейским судам, медиаторам, установлен- ными и закрепленными различными актами согласительным комиссиям) по разрешению спора за иными, несудебными, инстанциями. При этом можно условно определить административный внесудебный и внеадминистративный порядки разрешения споров. В узком смысле (в рамках управленческой деятельности) разрешение споров в административном порядке выделяется как одна из функций управления и упорядочения публичного администрирования, и эта деятельность является одним из организационно-правовых механизмов, осуществляемых в процессе государственного регулирования и управления органами исполнительной власти.

Статья 33 Конституции РФ гласит, что «Граждане Российской Федерации имеют право обращаться лично, а также решение индивидуальные и коллективные обращения в государственные органы и органы местного самоуправления» [1]. Это право граждан является одним из ключевых элементов их административного и правового статуса. Государственные органы должны быть в состоянии своевременно и объективно реагировать на жалобы граждан. 
Учитывая то, что структура административно-правового спора состоит не только из субъектов и предмета конфликта, но и непосредственно включает упорядоченный нормами права процесс противоборства участвующих в споре сторон, посредством которого реализуются цели и задачи спора, необходимо детальное и упорядоченное регламентирование всех стадий процесса по разрешению возникших противоречий. Нарушения прав и свобод граждан могут проявляться в различных формах. Наиболее распространены споры граждан и юридических лиц в связи с решениями органов исполнительной власти и действиями (бездействием) их должностных лиц.

На современном этапе масштабного и динамичного обновления законодательства России в различных отраслях права одним из основных направлений в административном праве, по мнению автора является введение и обособленное становление института административной юстиции, которая представляет собой правовой институт судебной защиты прав, свобод граждан, законных интересов юридических лиц и других организаций путем осуществления контроля за соблюдением законности в системе государственного управления.

В мировой практике административная юстиция существует в различных организационных формах. Перенос их в том виде, в котором они функционируют в зарубежных странах, вряд ли можно считать целесообразным. Рассматриваемый институт должен вписаться в правовую систему России органично. Следует подчеркнуть, что институт административной юстиции становится одним из основных элементов современного правового государства и призван осуществлять судебный контроль за деятельностью органов исполнительной власти в целях наилучшей защиты публичных прав личности. Необходимость административной юстиции как механизма правовой защиты проистекает из потребности обеспечить законные интересы граждан во всех случаях неправомерного и бесконтрольного использования властных полномочий административными органами и их должностными лицами [6, с. 2]

Административная юстиция призвана выполнять в обществе и государстве функцию судебного контроля, не только в порядке административного судопроизводства путем возбуждения и рассмотрения судом споров по искам граждан, юридических лиц и организаций, но и путем развития досудебного и внесудебного порядка урегулирования публичных споров с целью предупреждения и обеспечения соблюдения исполнения законов и установленных правил органами государственного управления, местного самоуправления, если в соответствии с законом им делегировано осу- ществление государственных функций, а также некоторых споров между государственными органами и органами местного самоуправления. Административный порядок разрешения спора, как и судебный контроль за деятельностью органов исполнительной власти, является одним из основных элементов правового государства. Специфика этой деятельности, заключается в том, что он осуществляется в определенных формах, обусловленных особенностью взаимоотношений двух самостоятельных ветвей власти: исполнительной и судебной, и ее целью является с одной стороны защита физических, юридических лиц и других организаций от злоупотреблений властью со стороны органов государственного управления и должностных лиц, а с другой стороны - улучшение качества деятельности органов государственного управления в интересах граждан, юридических лиц, организаций и общества в целом. Таким образом можно утверждать, что в современном Российском обществе происходящие процессы конфигурации сферы административно-правового воздействия постепенно изменились с утверждением демократических ценностей, гуманизацией публичного управления и переходом страны к рыночной экономике, о чем также свидетельствуют произошедшие изменения в действующем законодательстве. Принятие в 2015 году Кодекса Административного Судопроизводства наглядно демонстрирует открытость и заинтересованность ветвей власти к разрешению административно-правовых споров. В частности принцип состязательности сформулирован в кодексе административного судопроизводства с учетом активной роли суда в процессе, который осуществляет руководство судебным процессом, разъясняет каждой из сторон ее права и обязанности, предупреждает о последствиях совершения или несовершения сторонами процессуальных действий, оказывает им содействие в реализации их прав, создает условия и принимает предусмотренные настоящим кодексом меры для всестороннего и полного установления всех фактических обстоятельств по административному делу, в том числе для выявления и истребования по собственной инициативе доказательств, а также для правильного применения законов и иных нормативных правовых актов при рассмотрении и разрешении административного дела. Кроме того, система защиты и восстановления нарушенных прав позволяет избежать необходимости повторного обращения за судебной защитой с отдельным требованием.

Постоянно идет процесс наращивания присутствия государства и совершенствования институтов административного права в тех областях жизни, где это необходимо для укрепления общественного порядка и законности с учетом соблюдения прав и свобод человека и гражданина, закрепленных в основных зако- 
нах государства. По мнению автора, трансформация концепции административных правоотношений имеет тенденцию к гуманизации публичного управления, повышения доверия к органам исполнительной власти, что еще раз говорит о необходимости развития института досудебного урегулирования спора, внедрению альтернативных способов урегулирования разногласий в области публичного администрирования. Если взглянуть на многие зарубежные страны, мы видим, что, механизм альтернативных способов разрешения споров уже отделен от судебного контроля.

Как упоминалось ранее в Рекомендациях Комитета министров Совета Европы REC (2001) предлагается обратить внимание на меры облегчения доступа к правосудию, которые выражались бы в виде «.мер поощрения использования примирения и посредничества», а также о «мерах по предотвращению и сокращению чрезмерной нагрузки на суды, которая предусматривает в соответствующих случаях использование дружественного урегулирования споров, либо вообще вне судебной системы, либо до судопроизводства или в ходе его» [7].

Нужно отметить, что такие альтернативные способы разрешения административных споров, которые является неюрисдикционными не заменяют административные суды, а лишь являются дополнением, при этом разгружая не только суд, но и административную процедуру по обжалованию административного акта. Во многих странах, альтернативные способы разрешения споров получили законодательную регламентацию, следовательно, в Российском законодательстве, они не должны оставаться не замеченными.

Досудебный порядок (в некоторых источниках, внесудебный порядок) характеризует процедуры защиты прав, которые используются до обращения в суд.

В последние годы в юридической науке и законодательном процессе вызывает интерес неюрисдикционные способы разрешения споров в публично-правовых отношениях. Используемый в научном обороте термин «альтернативные способы разрешения споров», в законодательстве многих стран носят легитимный характер. Поэтому заимствование данного термина вполне обусловлено взаимопроникновением правовых систем.

В административном производстве наиболее важной и при этом наименее законодательно урегулированной частью является досудебное производство. Принятый КАС РФ в 2015 г. содержит нормы по урегулированию спора при рассмотрении искового заявления, однако по мнению автора этого явно недостаточно для рассмотрения вопроса по урегулированию спора во внесудебном порядке.
Современная правовая политика направлена на развитие внесудебных форм разрешения споров, максимальное урегулирование спора на досудебных стадиях, защиту прав заявителей не только судебными, но, в первую очередь, компетентными вышестоящими административно-правовыми органами, которые могут устранить ошибку, если она была допущена, путем установления правомерности решения, но и целесообразности его принятия.

В этой связи автор предлагает дополнительно разработать и закрепить в КАС РФ положение о том, что подача некоторых заявлений в суд возможна после:

- предварительного административного производства

- обращения в квазисудебные органы, сформированные в рамках административной юстиции

- прохождения внесудебного порядка урегулирования спора

В рамках закона могут быть предусмотрены исключительные случаи, когда предварительное административное производство не осуществляется и дело подлежит рассмотрению только судом. В качестве примера можно сослаться на трудовое законодательство РФ, которым предусмотрены согласительные (примерительные) комиссии по разрешение трудовых споров, обращение в которые регламентированы законодательством и являются обязательным условием при подаче иска в суд.

Для более детального осмысления предварительной процедуры внедрения такого новшества автор предлагает обратить внимание на зарубежный опыт административного разрешения публичных споров и с учетом вековых традиций российского общества разработать и внедрить на базе сформированной административной юстиции свои правила и подходы внесудебной и досудебной процедуры урегулирования административного спора.

При разработке концепции внедрения альтернативных способов разрешения публичных споров необходимо различать и разграничить внесудебные и досудебные способы урегулирования споров.

По мнению автора эффективным представляется введение аккредитации медиации при содействии органов юстиции. Такая аккредитация смогла бы обеспечить квалифицированную помощь сторонам конфликта. При этом список аккредитованных медиаторов следовало бы размещать на информационных сайтах и сайте судов.

Также автор исследования кроме аккредитации медиаторов предлагает внести дополнительные тре- 
бования к квалификации профессиональных медиаторов в виде обязательного наличия высшего юридического образования. Статью 16 ч. 1 Федеральный закон от 27.07.2010 N193-Ф3 «О6 альтернативной процедуре урегулирования споров с участием посредника (процедуре медиации)» изложить в следующей редакции: «Осуществлять деятельность медиаторов на профессиональной основе могут лица, достигшие возраста двадцати пяти лет, имеющие высшее юридическое образование и получившие дополнительное профессиональное образование по вопросам применения процедуры медиации.» Данная поправка повысит доверие к процедуре внесудебного порядка урегулирования спора и в перспективе может послужит базой для придания медиативному соглашению юрисдикционной нормы.

По мнению автора, в действующем гражданском законодательстве России по проведению процедуры медиации необходимо обозначить ее как самостоятельный способ защиты прав, доработав законодательную базу, в частности закрепить требования к профессиональному (юридическому) образованию медиатора, к курсам, на которых обучаются медиаторы (установить порядок обучения и аккредитации); определить необходимые требования к организациям, которые оказывают услуги по медиации. Данную подготовку по обучению медиаторов, проводить ориентируясь на программу подготовки, утвержденную Министерством Образования РФ. В данном обзоре автор проводит исследования в области внесудебного порядка разрешения спора между субъектами публичного права, а также предлагает введение альтернативного способа разрешения административно-правовых споров путем развития и внедрения квазисудебных органов, рассматривая их с точки зрения, как уполномоченного юрисдикционными правами альтернативного субъекта внесудебного урегулирования конфликта сторон публичных правоотношений.

В последнее наблюдается тенденция участников спорных правоотношений в самостоятельном урегулировании возникающих противоречий с использованием альтернативных способов разрешения споров. Под альтернативными способами разрешения правовых конфликтов понимается совокупность определенных приемов и методов внесудебного урегулирования споров, в результате их применения стороны заключают взаимоприемлемое соглашение [9, с. 360]. При этом данный термин указывает на наличие негосударственной внесудебной защиты прав граждан с использованием в ее рамках определенных средств. Следовательно, использование понятия «альтернативный» сопряжено с некоторой субсидиарностью, дополнительностью этих средств по отношению к государственной судебной защите прав граждан.
Как ранее было отмечено в Российской правовой практике альтернативное разрешение споров условно разделяется на досудебное и внесудебное.

На сегодняшний день область применения медиации как внесудебного урегулирования противоречий сторон становится все шире. Рассматривается и широко обсуждается новый способ примирения сторон с участием адвокатов (партисипативная процедура).

Представляется, что одним из возможных путей совершенствования системы рассмотрения административных и иных публично-правовых споров является внедрение технологии и процедуры медиации в деятельность уполномоченных органов и должностных лиц. При этом более успешно могут быть урегулированы при помощи медиации административные споры, где не требуется толкование норм права, применение санкций за злоупотребление полномочиями, а также споры об индивидуальных административных актах.

Рассматривая данный вопрос необходимо отметить, что возможность проведения примирительных процедур и заключения мирового соглашения по спорам, вытекающим из административно-публичных отношений, в настоящее время является дискуссионным, что порождает дуалистические взгляды ученных-теоретиков и правоприменителей к такому подходу. На сегодняшний день в российской процессуальной науке сложилось две противоположных позиции. Сторонники одной позиции, отвергают возможность использования примирительных процедур по административным делам. Сторонники применения примирительных процедур основываются на положительном опыте Германии и других зарубежных стран. Для более объективного восприятия точки соприкосновения медиации и удачного разрешения административных споров, необходимо обратить внимание к зарубежной практике.

Как ранее было указано Федеральный закон от 27 июля 2010 года № 193-Ф3 «Об альтернативной процедуре урегулирования споров с участием посредника (процедуре медиации)» не содержит запрета на проведение медиации по публично-правовым спорам. В то же время согласно части 3 статьи 1 указанного Закона регламентировано применение медиации для урегулирования таких споров только в случаях, установленными федеральными законами. Хотя и законодательством РФ пока не предусмотрено альтернативных форм разрешения споров по налоговым и административным делам, но можно уверенно констатировать что в настоящее время ведутся конструктивные дискуссии о возможности применения медиации в сфере административного права, в частности при разрешении налоговых споров [13, с. 304]. 
Следует отметить, что российское законодательство уже сегодня предусматривает урегулирование административных и иных публично-правовых споров в порядке примирительных процедур. Существует уже целый ряд случаев, когда спор с государственным органом был урегулирован в порядке примирительной процедуры (переговоров) с заключением в итоге мирового соглашения. Так, согласно ст. 190 Арбитражного процессуального кодекса РФ предусмотрено, что экономические споры, возникающие из административных и иных публичных правоотношений, могут быть урегулированы сторонами по правилам, установленным в главе 15 данного кодекса, путем заключения соглашения или с использованием других примирительных процедур, если иное не установлено федеральным законом. П. 2 указанной статьи предусмотрено: «В случаях, если до обращения в арбитражный суд с требованиями об оспаривании ненормативных правовых актов, решений и действий (бездействия) органов, осуществляющих публичные полномочия, и должностных лиц, о взыскании обязательных платежей и санкций стороны не использовали досудебное урегулирование спора, арбитражный суд вправе при согласии организации, индивидуального предпринимателя или гражданина в целях примирения сторон и уточнения фактических обстоятельств, снятия противоречий в позициях, в том числе путем проведения сверки взаимных расчетов, отложить судебное разбирательство в порядке, установленном настоящим Кодексом, предложив сторонам использовать примирительную процедуру, в том числе с участием судебного примирителя.» [5]

Для усовершенствования данного вопроса автор предлагает дополнить и внести изменения в некоторые нормы действующего законодательства закрепляющие правовой статус медиаторов при разрешении спора не только в области гражданско-правовых отношений, но и при разрешении публичных споров.

Помимо предложенного внесения изменения в норму ч. 1 ст. 16 Федерального закона от 27.07.2010 N193-
Ф3 «Об альтернативной процедуре урегулирования споров с участием посредника (процедуре медиации)» об обязательном наличии высшего юридического образования у профессиональных медиаторов, предлагается в этом же законе определить и конкретизировать перечень дел подлежащих медиации профессиональными и непрофессиональными медиаторами.

Как свидетельствует опыт зарубежных стран, одним из направлений реформирования системы разрешения публично-правовых споров может стать именно внедрение и развитие альтернативных (внесудебных) способов разрешения спора.

Более того для внедрения и развития внесудебного порядка урегулирования спора, впрочем как и становление и обособление административной юстиции России в целом, развития ее как самостоятельного института необходимо изменение не только порядка взаимодействия государства и граждан, но и внутриведомственных структур, реформирование судебной власти путем выделения административного судопроизводства в отдельную процедурно-процессуальную отрасль по осуществлению судебного контроля и разрешению административно-правовых споров в области публичного администрирования.

Думается, что внесудебные методы разрешения административно-правовых споров, порядок их применения и внедрения в повседневную практику заслуживает особого внимания отечественных ученных-административистов по крайней мере в силу двух причин.

Внесудебный порядок, а равно альтернативные способы разрешения административных споров успешно используется во многих странах и получает необходимую законодательную регламентацию. Соответственно, вопросы возможности, пределов и особенностей применения указанных методов в Российском законодательств, по общему мнению, не должны остаться без внимания.

\section{ЛИТЕРАТУРА}

1. «Конституция Российской Федерации» (принята всенародным голосованием 12.12.1993 с изменениями, одобренными в ходе общероссийского голосования 01.07.2020)

2. АПК РФ от 04.07.2002 года N95-Ф3

3. КАС РФ от 08.03.2015 № 21-Ф3

4. Конституционное право: восточноевропейское обозрение.-2002. № 3.

5. АПК РФ от 04.07.2002 года N95-Ф3

6. Радченко В.И. Административные суды призваны защищать человека от произвола недобросовестных чиновников // Российская юстиция. 2004 . № 3.

7. «Судебная система Российской Федерации» Сборник нормативных актов, М., 2004 год

8. Исаенкова 0.В. Развитие медиации в Российской Федерации: проблемы и перспективы // Вопросы российского и международного права. - 2013. № 3 
9. Адвокат: навыки профессионального мастерства / Под ред. Л.А. Воскобитовой, И.Н. Лукьяновой, Л.П. Михайловой. М.: ВолтерсКлувер, 2006.

10. Давыденко Д.Л. Мировое соглашение как средство внесудебного урегулирования частноправовых споров (по праву России и некоторых зарубежных стран): Дис. ... канд. юрид. наук. М., 2004

11. Борисова Е.А. Российская процедура медиации: концепция развития // Вестник Московского университета. Серия 11. Право. 2011. N5.

12. Бесспорные выгоды. Медиация в голландской налоговой системе/ Медиация и право. — 2009. — № 2.

13. Калашникова С.И. Медиация в сфере гражданской юрисдикции. - М.: Инфотропик Медиа, 2011.

14. Обзор судебной практики ВС РФ № 4 (2020) от 23.12.2020 г.п. 24

15. Обзор судебной практики ВС РФ № 4 (2020) от 23.12.2020 г. определение № 301-ЭС20-5798

16. Зеленцов А.Б. Административно-правовой спор: вопросы теории: Монография. Изд. 2-е, испр. и доп. — М.: РудН, 2009.

(c) Терновский Виталий Анатольевич ( vat13list@mail.ru ).

Журнал «Современная наука: актуальные проблемы теории и практики»

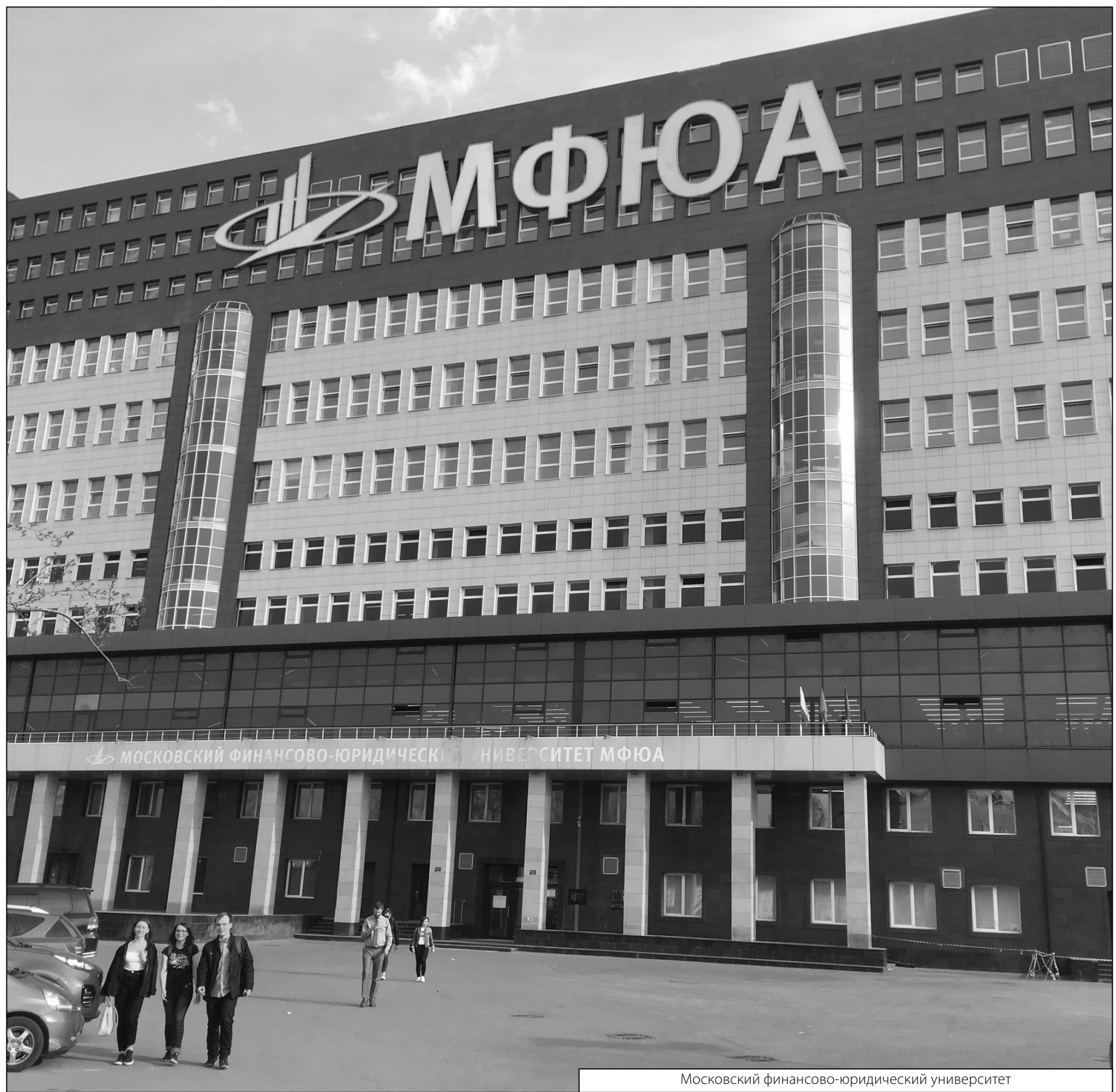

